\title{
Antepartum Eclampsia and Partial HELLP Syndrome in a Patient with Bell's Palsy
}

\author{
${ }^{1}$ Kriti Agarwal, ${ }^{2}$ Krishna Dahiya
}

\begin{abstract}
Bell's palsy affects pregnant women three times more often than nonpregnant women, with majority of cases occurring in the third trimester $(71 \%)$ and early postpartum period $(21 \%)$. Bell's palsy during pregnancy has been associated with preeclampsia, with $22 \%$ of these women developing preeclampsia. A 26 -year-old G3P1L1A1 presented at 33 weeks period of gestation with chief complaint of progressive bilateral pedal edema since a week, blood pressure (BP) 150/100 mm Hg, dipstick urine 3+. Labetalol $100 \mathrm{mg} 12$ hourly was commenced for control of BP. Laboratory screening of HELLP (hemolysis, elevated liver enzymes, and low platelet count) syndrome was normal. Six days later she had an episode of generalized tonic-clonic convulsion, magnesium sulfate was given and emergency laboratory investigations revealed partial HELLP syndrome [platelet 80,000 , serum glutamic oxaloacetic transaminase (SGOT)/serum glutamic pyruvic transaminase (SGPT) 281/222 U/L] with normal coagulation profile. Lower segment cesarean section was done under general anesthesia with delivery of a $2 \mathrm{~kg}$ baby with Apgar score of $7 / 10$ and $9 / 10$ at 1 and 5 minutes respectively. Postoperative day 3 , all laboratory reports including magnetic resonance imaging (MRI) brain were normal. Blood pressure was stabilized and she was discharged on third postnatal day, with some right-sided residual facial weakness. All obstetricians must be aware of association of Bell's palsy with hypertensive disorders of pregnancy and aggressive screen for the same as soon as diagnosed, in order to prevent complications like eclampsia and HELLP. Since Bell's palsy is not associated with adverse perinatal outcomes, it should not prompt obstetricians for unnecessary preterm inductions.
\end{abstract}

Keywords: Antepartum eclampsia, Bell's palsy, Partial HELLP.

How to cite this article: Agarwal K, Dahiya K. Antepartum Eclampsia and Partial HELLP Syndrome in a Patient with Bell's Palsy. World J Anemia 2018;2(1):34-35.

Source of support: Nil

Conflict of interest: None

\section{INTRODUCTION}

Bell's palsy is an idiopathic lower motor neuron type of facial paralysis. Pregnant women are affected three times

\footnotetext{
${ }^{1}$ Senior Resident, ${ }^{2}$ Professor

1,2Department of Obstetrics and Gynecology, Pt. Bhagwat Dayal Sharma Post Graduate Institute of Medical Sciences, Rohtak Haryana, India

Corresponding Author: Kriti Agarwal, Senior Resident Department of Obstetrics and Gynecology, Pt. Bhagwat Dayal Sharma Post Graduate Institute of Medical Sciences, Rohtak Haryana, India, e-mail: kriti.leo@gmail.com
}

more often than nonpregnant women, with majority of cases occurring in the third trimester $(71 \%)$ and early postpartum period $(21 \%)$, which coincides with period of maximum fluid overload, leading to compression neuropathy in places where the nerves course in a narrow spacelike fallopian canal, causing mechanical compression of facial nerve. ${ }^{1,2}$ Pregnancy is a hypercoagulable state, and thrombosis of vasa nervosa of facial nerve leading to ischemic injury can also lead to more frequent occurrence of Bell's palsy in pregnancy. ${ }^{3}$ Bell's palsy during pregnancy has been associated with preeclampsia. ${ }^{2}$ It can either precede preeclampsia-eclampsia syndrome in the antepartum period or it can occur postpartum too. We report a case of Bell's palsy in pregnancy, leading to antepartum eclampsia and partial HELLP syndrome with spontaneous recovery.

\section{CASE REPORT}

A 26-year-old G3P1L1A1 presented at 33 weeks period of gestation with chief complaint of progressive and bilateral pedal edema since a week. She had completed a course of oral steroids for Bell's palsy, diagnosed 2 weeks ago, by general practitioner. At presentation, BP was $150 / 100 \mathrm{~mm} \mathrm{Hg}$, dipstick urine was 3+, without features of impending eclampsia. Chest and cardiovascular examination was normal. Uterus was 32 weeks in size, and fetal heart rate was $140 / \mathrm{min}$. Opinion was taken from the neurologist regarding Bell's palsy. She was advised physiotherapy and prescribed multivitamins, eye cover, eye drops. Labetalol $100 \mathrm{mg} 12$ hourly was commenced. Fundus was normal. She was screened for laboratory features of HELLP syndrome, with results as follows:

Hemoglobin $(\mathrm{Hb})$ was $12.2 \mathrm{gm} / \mathrm{dL}$, platelet 2.0 lakh, peripheral smear showed normocytic normochromic picture, blood urea $38 \mathrm{mg} / \mathrm{dL}$, serum creatinine $0.8 \mathrm{mg} / \mathrm{dL}$, SGOT/SGPT 49/56 U/L, serum bilirubin $0.4 \mathrm{mg} / \mathrm{dL}$, lactate dehydrogenase (LDH) $200 \mathrm{IU} / \mathrm{mL}$, international normal ratio (INR) 1.13.

Six days later she had an episode of generalized tonic-clonic convulsion, magnesium sulfate was given, and emergency laboratory investigations were sent with reports as follows: $\mathrm{Hb} 8 \mathrm{gm} / \mathrm{dL}$, platelet 80,000 , peripheral smear showed dimorphic picture predominantly macrocytes, blood urea $62 \mathrm{mg} / \mathrm{dL}$, serum creatinine $1.5 \mathrm{mg} / \mathrm{dL}$, SGOT/SGPT 281/222 U/L, serum bilirubin 
$0.5 \mathrm{mg} / \mathrm{dL}$, LDH $300 \mathrm{IU} / \mathrm{mL}$, INR 1.30. Provisional diagnosis of antepartum eclampsia and partial HELLP syndrome was made. She was taken up for lower segment cesarean section and delivered a $2 \mathrm{~kg}$ baby with Apgar score of $7 / 10$ and $9 / 10$ at 1 and 5 minutes. On postoperative day 3 , all lab reports including MRI brain were normal. Blood pressure was stabilized and she was discharged on third postnatal day, with some right-sided residual facial weakness.

\section{DISCUSSION}

There is a strong association between Bell's palsy and preeclampsia with $22 \%$ of these women developing preeclampsia. ${ }^{4,5}$ In fact, Ragupathy and Emovon ${ }^{6}$ suggested that both these conditions have the same etiopathogenesis of extracellular edema, and all cases of Bell's palsy have to be screened for preeclampsia. In our case, despite adequate screening for severe preeclampsia and stabilization of BP, antepartum eclampsia and HELLP syndrome could not be prevented. This can be due to the fact that patient presented to us 2 weeks after the diagnosis of Bell's palsy, and an opportunity of earlier screening for preeclampsia was missed. In our extensive search, we did not find any case report of Bell's palsy leading to antepartum eclampsia and partial HELLP syndrome simultaneously.

The prognosis for a satisfactory recovery was significantly worse for pregnant women than for the general population, predictors for poor outcome being bilateral disease and recurrence in subsequent pregnancy. ${ }^{1,7}$ Use of steroids is controversial in pregnancy. Some have found to improve recovery, ${ }^{8}$ especially if started within 24 hours, ${ }^{6}$ whereas others consider treatment with steroids as superfluous. ${ }^{2}$ Nevertheless, in this case, despite steroid therapy being started within 72 hours of onset of symptoms of Bell's palsy, residual weakness occurred postpartum. High rate of spontaneous recovery after delivery has been observed and this has been associated with higher levels of endogenous steroids during pregnancy, younger age of this population, and resolution of physiological and anatomical changes after birth of the baby. ${ }^{9}$ Whether drugs like magnesium sulfate used in preeclampsia can actually worsen the recovery of Bell's palsy needs to be investigated. ${ }^{10}$
There have been reports of low birth weight babies for mothers with Bell's palsy. ${ }^{4}$ However, a recent study concluded that, although Bell's palsy is associated with preeclampsia, it does not increase the incidence of adverse perinatal outcome. ${ }^{5}$ In our case too, baby had good Apgar score despite being preceded by eclampsia and effect of drugs used for general anesthesia.

\section{CONCLUSION}

All obstetricians must be aware of association of Bell's palsy with hypertensive disorders of pregnancy and aggressively screen for the same as soon as diagnosed, in order to prevent complications like eclampsia and HELLP syndrome. Since Bell's palsy is not associated with adverse perinatal outcomes, it should not prompt obstetricians for unnecessary preterm inductions.

\section{REFERENCES}

1. Cohen Y, Lavie O, Granovsky-Grisaru S, Aboulafia Y, Diamant YZ. Bell palsy complicating pregnancy: a review. Obstet Gynecol Surv 2000 Mar;55(3):184-188.

2. Shapiro JL, Yudin MH, Ray JG. Bell's palsy and tinnitus during pregnancy: predictors of pre-eclampsia? Three cases and a detailed review of the literature. Acta Otolaryngol 1999 Feb;119(6):647-651.

3. Davies PW, Vallejo MC, Shannon KT, Amortegui AJ, Ramanathan S. Oral herpes simplex reactivation after intrathecal morphine: a prospective randomized trial in an obstetric population. Anesth Analg 2005 May;100(5):1472-1476.

4. Shmorgun D, Chan WS, Ray JG. Association between Bell's palsy in pregnancy and pre-eclampsia. QJM 2002 Jun;95(6):359-362.

5. KatzA,Sergienko R, Dior U, Wiznitzer A, Kaplan DM, Sheiner E. Bell's palsy during pregnancy: is it associated with adverse perinatal outcome? Laryngoscope 2011 Jul;121(7):1395-1398.

6. Ragupathy K, Emovon E. Bell's palsy in pregnancy. Arch Gynecol Obstet 2013 Jan;287(1):177-178.

7. Gillman GS, Schaitkin BM, May M, Klein SR. Bell's palsy in pregnancy: a study of recovery outcomes. Otolaryngol Head Neck Surg 2002 Jan;126(1):23-30.

8. Ramsey MJ, DerSimonian R, Holtel MR, Burgess LP. Corticosteroid treatment for idiopathic facial nerve paralysis: a meta-analysis. Laryngoscope 2000 Mar;110(3 Pt 1):335-341.

9. Aditya V. LMN facial palsy in pregnancy: an opportunity to predict preeclampsia-report and review. Case Rep Obstet Gynecol 2014 Mar;2014:626871.

10. Lee C, Zhang X, Kwan WF. Electromyographic and mechanomyographic characteristics of neuromuscular block by magnesium sulphate in the pig. Br J Anaesth 1996 Feb;76(2):278-283. 